\title{
An overview of fast dc-dc converters for envelope amplifier in RF transmitters
}

\author{
O. García, M. Vasic, P. Alou, J.A. Oliver, J.A. Cobos
}

\begin{abstract}
In the last years, RF power amplifiers are taking advantage of the switched dc-dc converters to use them in several architectures that may improve the efficiency of the amplifier, keeping a good linearity. The use of linearization techniques such as Envelope Elimination and Restoration (EER) and Envelope Tracking (ET) requires a very fast dc-dc power converter to provide variable voltage supply to the power amplifier but theoretically the efficiency can be much higher than using the classical amplifiers belonging to classes $\mathrm{A}, \mathrm{B}$ or $\mathrm{AB}$.

The purpose of this paper is to analyze the state of the art of the power converters used as envelope amplifiers in this application where a fast output voltage variation is required. The power topologies will be explored and several important parameters such as efficiency, bandwidth and output voltage range will be discussed.
\end{abstract}

\section{INTRODUCTION}

There are several applications that need a power dc-dc converter with variable output voltage. In Dynamic Voltage Scaling (DVS), the converter provides power to a digital circuit that configures its own supply voltage in order to optimize the autonomy when it is battery operated or decrease the power losses. The converter modifies its output voltage dynamically following the requirements of the load. When a fast change is needed, the converter should be designed paying attention to this particular aspect together with the rest (voltage ripple, dynamic response).

In the recent years, another application that is using a variable output voltage dc-dc converter is RF power amplifiers (RFPA). The solutions for the high frequency power amplifiers can be classified in two different families: linear and nonlinear. The linear power amplifiers (PA) A, B or AB are known to be highly linear, but inefficient solutions especially if the average amplitude is small compared with the supply voltage. On the other hand, the nonlinear power amplifiers have high power efficiency and their output is a sinusoidal signal with constant envelope. They are based on the idea to use transistors as switches instead as a current source. In that way the power losses of the devices are lower and these amplifiers are presented with classes C, D, E and F.

The Kahn's technique [1][2][3] (or Envelope Elimination and Restoration EER) has showed that it is suitable to provide high linearity (using a non linear power amplifier such as class

This work has been founded by the Ministerio de Ciencia e Innovación of Spain under the project TEC2009-14307-C02-01.
E for example) and to provide relatively high efficiency. This technique is based on the use of one highly efficient but nonlinear power amplifier for the phase modulation, together with an envelope amplifier (EA) that should have high efficiency and provide envelope modulation by modulating the voltage supply of the non linear power amplifier, see figure 1 .

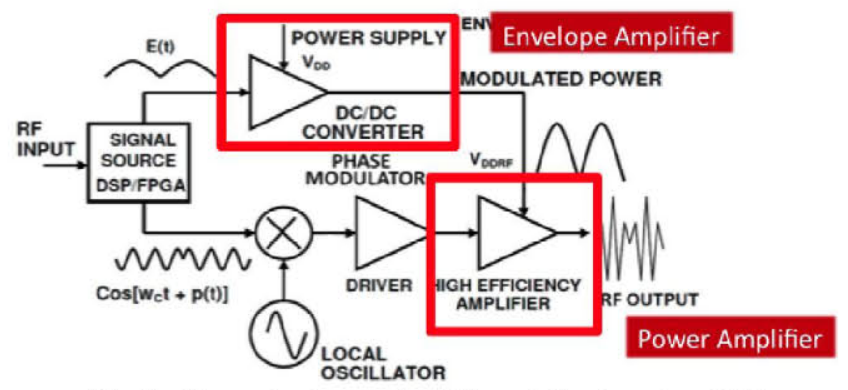

Fig 1.- General scheme of a RF amplifier based on EER

The EA is a dc-dc power converter that should track dynamically the envelope with accuracy and it is therefore a very challenging circuit. The converter should be designed with a small filter to be able to change its output voltage very fast but it also needs to have very small ripple. Therefore, in most of these circuits, a high switching frequency is required reducing the efficiency of the converter. Although in most of the cases a simple topology can be used, the constant needs of increasing the bandwidth and the output power force the designers to propose alternatives to these first-option topologies.

Also Envelope Tracking (ET) technique requires a fast dcdc converter to supply power to the power amplifier but, in this case, the PA is linear (class A for instance) and then, the EA can be slower and less accurate because the only requirement is to supply the PA with a voltage higher than the envelope to avoid the saturation of the output stage of the PA. The higher the accuracy of the EA, the better the efficiency but in principle, the ET structure offer a smaller efficiency compared with EER. Most of the ideas that may work in EER are also valid for ET.

There are many communications that can be improved with this techniques such as $3 \mathrm{G}$, digital audio and video broadcasting DAB-DVB, Wifi, Wi-Max, satellite communications, etc. The requirements of them in terms of bandwidth and power will be addressed in the final version of the paper but depending on the case, the envelopes require 
power from tens of Watts to $\mathrm{kW}$ and bandwidth form hundreds of $\mathrm{kHz}$ to tens of $\mathrm{MHz}$.

\section{Classification Of The Solutions for Fast Output} VOLTAGE VARIATION

\begin{tabular}{|c|c|c|c|}
\hline \multicolumn{2}{|c|}{ Group } & Topology & Linear regulator \\
\hline \multirow{2}{*}{ A } & A.1 & Buck (or boost) converter & None \\
\cline { 2 - 4 } & A.2 & Buck (or boost) converter & Parallel \\
\hline B & & Three level converter & None \\
\hline C & & Multilevel converter & Series \\
\hline \multirow{2}{*}{ D } & D.1 & Multi input converter & None \\
\cline { 2 - 4 } & D. 2 & Multi input converter & Parallel \\
\hline \multirow{2}{*}{ E } & E.1 & Multiphase converter & None \\
\cline { 2 - 4 } & E. 2 & Multiphase converter & Series \\
\hline
\end{tabular}

Table 1.- Summary of topologies for EA in the state of the art

The table 1 shows a classification of many of the topologies for fast output voltage variation that can be found in the state of the art applied to reference tracking and used in ET or EER.
In this section these solutions are analyzed and they are showed in figure 2 . In this figure, most of the diodes are implemented with controlled switches (MOSFETs due to the high switching frequency) but we keep the diodes for a better understanding of the circuits.

A.1- High Frequency Buck or Boost Converter: first of all, it is necessary to remind that the purpose to use any linearization technique such as EER or ET is to improve the efficiency. Therefore, most of the designs of the state of the art are based on the buck or the boost topology because these topologies are the best candidates to achieve a high efficiency (their switches have the smallest product between blocking voltage and dc current). These solutions are very well known but it should be kept in mind that using a single converter, the switching frequency should be at least 5 to 10 times higher than the required bandwidth for the envelope and therefore, the efficiency is penalized.

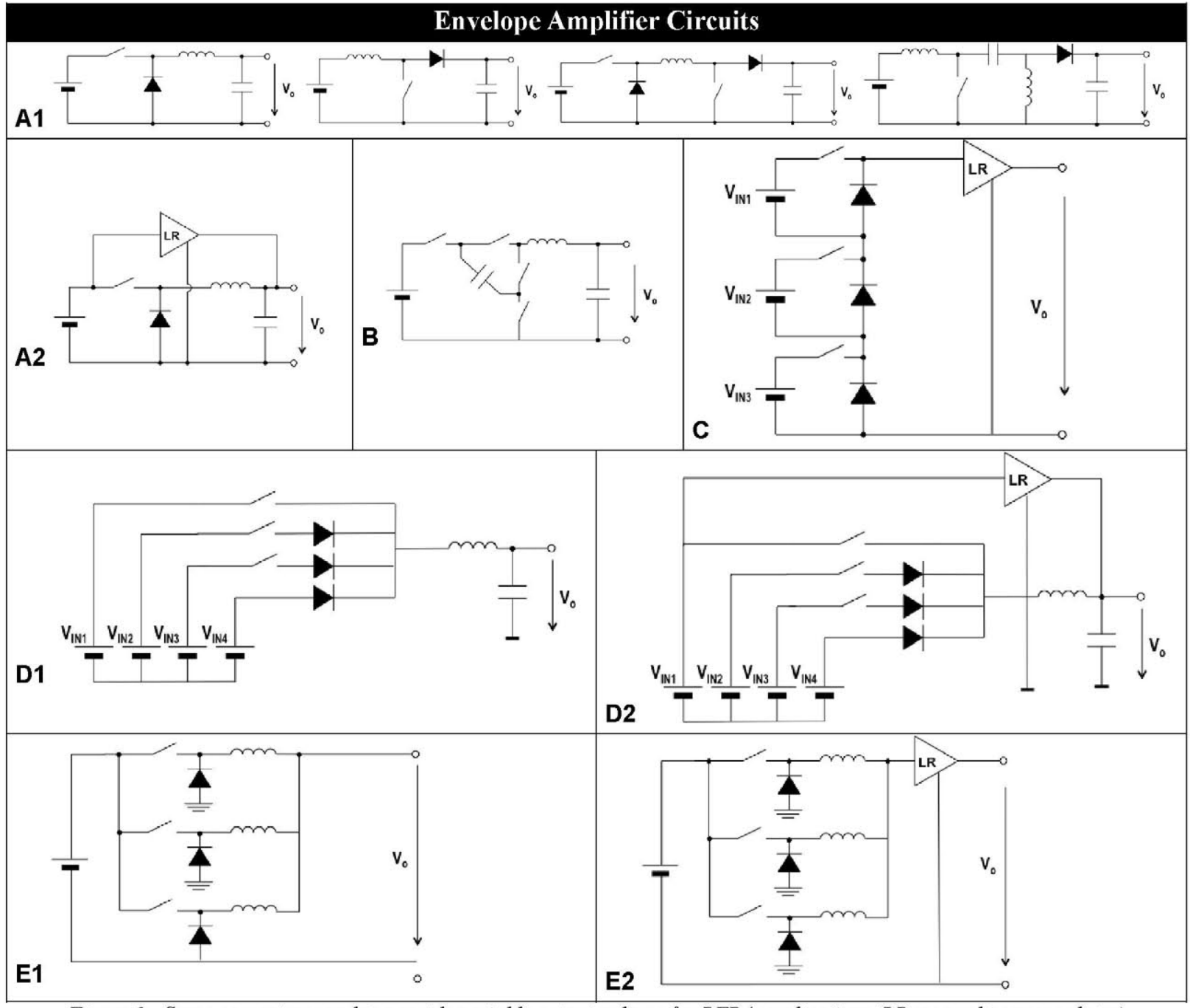

Figure 2.- Some converters used to provide variable output voltage for RFPA applications (LR means linear regulator) 
Reference [4] presents a buck converter with a double LC filter for envelope tracking in an audio application. The frequency of the envelope is small $(50 \mathrm{kHz})$ but the power is very high for this type of applications (500W). Since the application does not demand a high bandwidth, the switching frequency is not extremely high $(1.15 \mathrm{MHz})$ allowing a very good efficiency $(80-95 \%)$. The four order filter helps to reduce the distortion of the envelope.

The proposals [5][6] are also based on the buck converter but for much smaller power level being possible the integration of the power converter together with the RF amplifier. In [5] a $130 \mathrm{MHz}$ buck converter is designed to achieve $15 \mathrm{MHz}$ bandwidth in an integrated EER system. The switching frequency is extremely high but the power is $2 \mathrm{~W}$. [6] shows another example for ET with smaller frequencies (bandwidth $160 \mathrm{kHz}$, switching $800 \mathrm{kHz}$ ).

A $10 \mathrm{MHz}-1 \mathrm{~W}$ boost converter is used in [7] as an envelope amplifier to modulate the supply voltage of a $950 \mathrm{MHz}$ power amplifier between $3 \mathrm{~V}$ and $10 \mathrm{~V}$. It presents a very simple scheme of ET providing an output voltage always higher than the required envelope. Since the topology is a boost converter, the minimum output voltage is clamped to the input voltage.

The proposal [8] is interesting because a buck converters is integrated with a boost allowing a very wide output voltage range. It has been tested working at $1.68 \mathrm{MHz}$ to track a $100 \mathrm{kHz}$ envelope supplying a variable output voltage above and below the input voltage. There are other examples that are able to increase or decrease the battery voltage such as the buck-boost presented in [9] and the SEPIC used in [10].

A.2.- Single de-de Converter plus Parallel Linear Regulator: the objective of achieving a high efficiency together with a very high bandwidth is extremely difficult due to the very high switching frequency to track the reference. Using a linear regulator in parallel with the switched converter allows following a fast envelope, being the linear part responsible of this [3]. The switched converter may work at reduced frequency to take care of the low frequency spectrum of the reference with a high efficiency. The linear regulator is placed in parallel providing the high frequency components of the envelope, being necessary to be bidirectional. Therefore, on one hand we have a high efficiency of the power topology but, on the other hand, the linear regulator penalizes the efficiency dramatically. Two issues are critical in this configuration: the division of the harmonic spectrum of the reference and the synchronization of both converters.

In [11][12] this configuration is used. Both parts of the envelope amplifier (switched and linear) work as voltage sources and their outputs are added. The filters are included obtaining a band separation in the range of $30 \mathrm{kHz}$. It is important to keep in mind that the ideal band separation will depend on the probability density and the efficiency optimization of the switched part but this analysis is not included.

A similar power stage is used in [13][14] but the switched converter is current controlled by means of a hysteretic loop with variable frequency switching in the $\mathrm{MHz}$ range. In [13], the contribution to the bandwidth provided by this stage is $200 \mathrm{kHz}$, and the linear part provides up to $50 \mathrm{MHz}$. A deep optimization of the envelope amplifier is carried out in [14].

In the case of designing the switched part only for low frequency, the maximum efficiency is not necessarily achieved when the switched converter is providing the load's average current. In fact, it depends strongly on the supply voltages of the linear regulator [15].

B.- Three-Level Buck Converter: this is an improved version of a regular buck converter. The use of two additional switches allows the generation of a voltage in a floating capacitor that is charged with a voltage between the input voltage and zero [16]. With this arrangement, the circuit can apply three different voltage levels to the filter (see figure 3 ) and to duplicate its frequency.

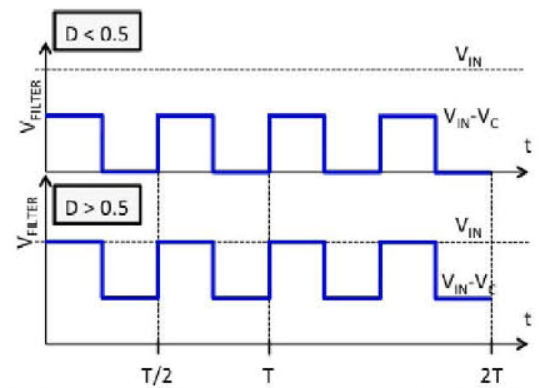

Figure 3.-Voltage waveform at the input of the LC filter using the three-level buck converter

The consequence is that the current ripple is reduced (or a smaller filter can be used) for the same power losses. It is used in an EER system. The authors compare the performance of this circuit with a two-phase buck converter, obtaining very similar results with the advantage of using a single inductor but with the drawback of higher conduction losses.

C.- Multilevel Converter plus Series Linear Regulator: other possibility is to use the series configuration proposed in [17]. The role of the switched converter is to make a first approximation of the envelope voltage from the input voltage in a low dissipative way. The input voltage is reduced dynamically according to the shape of the reference to reduce the power losses on the linear regulator (figure 4). The linear part will receive the same reference and it is the responsible of providing at its output the envelope required by the power amplifier.

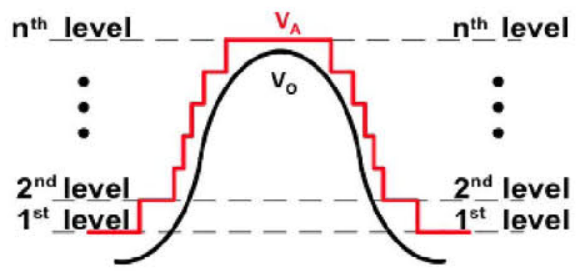

Figure 4.- Voltage waveform at the input of the linear rectifier and output voltage using the multilevel converter in series with a linear regulator 
In terms of efficiency this solution is better than a single linear regulator but it is necessary to obtain quite high efficiency in the switched part. The switched regulator can be implemented in many different ways [18]. It operates in openloop and its output will be only certain discrete voltage levels. These levels are achieved by stacking cells (see figure 2 ) or by an analog multiplexor. The main advantage is that the average switching frequency of these cells is much smaller than the frequency of the envelope (it depends on the probability density of the envelope), obtaining a high efficiency. The presence of the linear regulator makes unnecessary the output filter. These circuits have been proposed for an EER amplifier and this envelope amplifier provides $100 \mathrm{~W}$ peak power with $2 \mathrm{MHz}$ bandwidth. Moreover, they also may work well in an ET configuration by removing the linear regulator.

It is interesting the comparison between this solution where the linear regulator is in series and the solution A.2 where the linear regulator is in parallel [15]. In the series configuration to improve the efficiency a higher number of levels is required while in the parallel the efficiency is improved if the bandwidth of the switched part is improved. In both cases there is a trade-off since increasing the number of levels very much penalize the efficiency and improving the bandwidth forces to increase the switching frequency. In general terms, it can be said that the series approach may provide a better efficiency (around $10 \%$ ) by means of a higher complexity.

D.1.- Multiple-Input Converter: the idea is to have an analog multiplexor with several input voltages and select at every time one of these voltages to apply it to the LC filter. The analog multiplexor is implemented with one power MOSFETs and a series diode (to avoid the conduction of the body diode of the MOSFETs) in each branch but in the first and last branch it can be simplified. The reference [19] shows an example of this implementation in an ET amplifier.

This idea has several similarities with the previous one since they are based on applying certain voltage levels to the output but the objectives are different. In the first case this staircase is shaped by means of a linear regulator being possible to switch the MOSFETs at the envelope frequency but introducing some losses in the series element. In the second, the staircase is shaped using and LC filter to remove the high order harmonics; therefore it is less dissipative but the switches are forced to work with a frequency higher than the envelope, penalizing the efficiency.

D.2.- Multiple-Input Converter plus Parallel Linear Regulator: the previous idea can provide a higher bandwidth with the help of a parallel linear regulator [20] in a similar way than the group of ideas A.2. In this case, the connection between the linear and the switched part is made with the help of two antiparallel diodes. This is a simple solution but it introduces a small error in the feedback of the switched converter. The linear part is taking care of the load changes and therefore it controls the upper part of the frequency spectrum.
In these three last categories (C, D. 1 and D.2), it is the role of the designer to generate the auxiliary voltage levels from the available supply voltage. In a general case, there is only one voltage supply available and therefore, a multi-output converter should be included as a first stage to generated these voltage levels. The topology for this first stage may vary depending on the particular values of the voltages and we should consider the cross regulation of the outputs. The advantage is that since its dynamic requirements are none it can be designed with a low switching frequency to avoid a big penalization of the efficiency.

E.1.- Multiphase Converters: this type of converters allows to decouple the switching frequency of the output voltage ripple. The use of several shifted power stages (phases) can be a good solution due to their reduced output voltage ripple since usually this is one of the requirements for the envelope amplifiers. This solution has been used in [21] to track a $250 \mathrm{~W}-11 \mathrm{kHz}$ envelope by means of a 4-phases buck converter with very high efficiency. Regarding the bandwidth, it can be higher than its switching frequency in the multiphase converters but it is far of being the switching frequency multiplied by the number of phases as shown in [22].

E.2.- Multiphase Converters plus Series Linear Regulator: one of the latest developments is to combine a multiphase converter together with a series linear regulator like in topology C. The particularity of this option is that the multiphase converter operates with those discrete duty cycles that cancel its output current ripple. Thus, several discrete voltage levels are generated performing like the multilevel of option $\mathrm{C}$. The transitions from one level to other (change in the duty cycle) are carried out applying the minimum time theory; another advantage of this technique for this particular case is that thank to the operation with the duty cycles that cancel the ripple, the transition times do not depend on the current balance [23]. During a transient, the on and off times of each phase are the same but they are applied in different moments to keep the current balance after the transient (see figures 5 and 6).

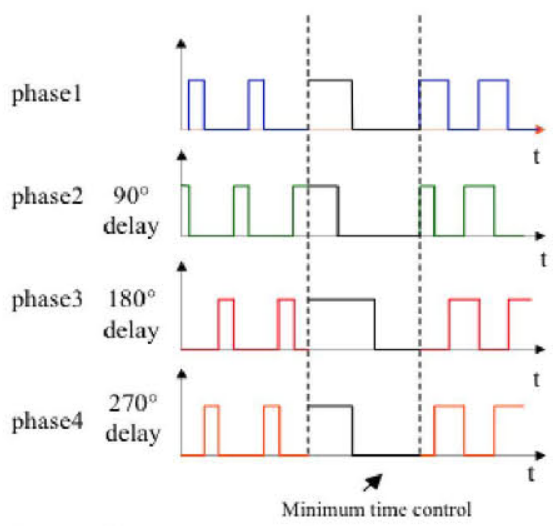

Figure 5.- Gate voltages of the multiphase converter working with discrete duty cycles applying minimum time technique in the transitions 


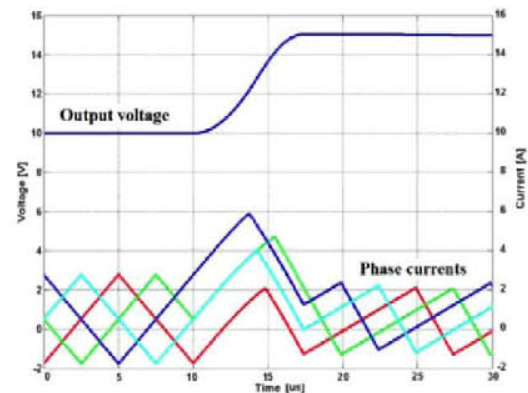

Figure 6.- Phase currents and output voltage during a transition

The problem of this solution is that if the transient should be very fast (very high bandwidth), the limited resolution of the digital control device maybe a restriction to perform the minimum time transition with accuracy. However this problem can be partially solved thanks to the cascaded linear regulator if the switched converter is configured to provide a little big higher voltage.

\section{TRADE-OFF BANDWIDTH-OUTPUT POWER}

Figure 7 shows a comparison of the solutions presented in the state of the art according to the trade-off envelope bandwidth and output power (note the log scale in both axis).

Classical topologies (group A.1) cover both parts high bandwidth (such as [5]) and high power [4] but not simultaneously. Including a parallel linear regulator (group A.2) makes easier to achieve a high bandwidth ([13][14]). The solution that presents a good trade-off between power and bandwidth is the one based on the multilevel with series regulator [17] (group C).

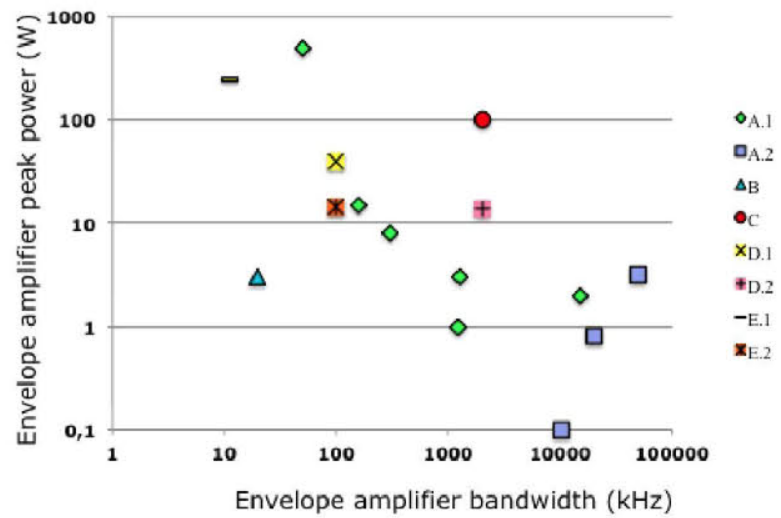

Figure 7.-Maximum bandwidth and peak power of the analyzed topologies for reference tracking

The use of new devices with lower switching losses may help to increase the efficiency of the switched converters for envelope amplification in higher bandwidth application. In particular GaN technology is suitable for this purpose. Some research groups are now testing $\mathrm{GaN}$ devices from EPC for improving dc-dc converters [24][25] and this application in particular [26]. The first results seem promising but, of course, the technology is not mature and better results are expected in the next future.

\section{CONCLUSIONS}

Dc-de converters with fast output voltage variation are becoming very used in RF as part of the EER or ET power amplifiers. In this application, the role of this converter (envelope amplifier) is to provide the envelope voltage for the power amplifier.

In most of the cases, the topology is a buck or a boost due to its high efficiency. However, when a high bandwidth is required, the switching frequency should be so high that the power losses limit the amount of power that these converters can provide.

For medium power range other alternatives can be found. All of them use several switches and are based on multiphase or multilevel converters. They are more complex but particular advantages can be obtained such as a reduced filter or a better efficiency.

In many cases, the use of a linear regulator in parallel with the switched converter improves the bandwidth very much by means of a small efficiency penalization, being very recommended in several applications.

The last option is to connect this linear regulator in series with the switched converter. This configuration allows the use of a power stage that may work at a reduced switching frequency because the voltage applied to the load (power amplifier) is shaped by the linear regulator. This solution shows a good trade-off between maximum power and bandwidth of the envelope.

Finally, many papers have been reported where the use of this switched converters in structures such as EER and ET, improve the efficiency of the RFPA in the range $5-20 \%$ compared with the classical amplifiers.

\section{REFERENCES}

[1] L.R. Khan, "Single-sideband transmission by envelope elimination and restoration", Proceedings of the I.R.E. July 1952, pp 803-806

[2] F.H. Raab, "Envelope elimination and restoration system requirements", GMRR TP87-4, pp.499-512.

[3] F.H. Raab, "Split-band modulator for Kahn-technique transmitters", IEEE MTT International Microwave Symposium 2004, pp.887-890.

[4] M.C.W.Hoyerby, M.A.E.Andersen, "Ultrafast tracking power supply with fourth-order output filter and fixed-frequency hysteretic control", IEEE Transactions on Power Electronics, Vol.23, No.5, Sep. 2008, pp 2387-2398.

[5] V. Pinon, F. Hasbani, A. Giry, D. Pache, C. Gamier, "A Single-Chip WCDMA Envelope Reconstruction LDMOS PA with $130 \mathrm{MHz}$ Switched-Mode Power Supply," Solid-State Circuits Conference, 2008. ISSCC 2008. Digest of Technical Papers. IEEE International, vol., no., pp.564-636, 3-7 Feb. 2008

[6] P. Midya, K. Haddad, L. Connell, S. Bergstedt, B. Roeckner, "Tracking power converter for supply modulation of RF power amplifiers", IEEE Power Electronics Specialists Conference PESC 2001, pp 1540-1545.

[7] G. Hanington, P.Chen, P.M. Asbeck, L.E. Larson, "High-Efficiency Power Amplifier Using Dynamic Power-Supply Voltage for CDMA Applications", IEEE Transactions on Microwave and Techniques, Volume 47, No. 8, August 1999. Pages: 1471-1476. 
[8] P. Midya, K. Haddad, M. Miller, "Buck or boost tracking power converter", IEEE Power Electronics Letters, Vol.2, No.4, December 2004, 131-134

[9] B. Sahu, G.A. Rincon-Mora, "A high efficiency linear RF power amplifier with a power tracking dynamically adaptive buck-boost supply", IEEE Transactions on Microwave Theory and Techniques, Vol.52, No.1, Jan. 2004.

[10] D.R. Anderson, W.H. Cantrell, "High-efficiency high-level modulator for use in dynamic envelope tracking CDMA RF power amplifiers", IEEE MTT-S International Microwave Symposium Digest, 2001 Vol.3, pp.1509-1512.

[11] V. Yousefzadeh, E. Alarcon, D. Maksimovic, "Band separation and efficiency optimization in linear-assisted switching power amplifiers", IEEE Power Electronics Specialists Conferfence 2006.

[12] N.Wang, X.Peng, V.Yousefzadeh, D.Maksimovic, S.Pajic, Z.Popovic, "Linearity of X-Band Class-E Power Amplifiers in EER Operation", IEEE Transactions on Microwave Theory and Techniques, Volume 53, No.3, March 2005, pages: 1096-1102.

[13] P.G. Blanken, R. Karadi, H.J. Bergveld, "A 50MHz Bandwidth MultiMode PA Supply Modulator for GSM, EDGE and UMTS Application", IEEE Radio Frequency Integrated Circuits Symposium, RFIC 2008, 1517 June 2008.

[14] F.Wang, D.F.Kimball, J.D.Popp, A.H.Yang, D.Y.Lie, P.M.Asbeck, L.E.Larson, "An Improved Power-Added Efficiency 19-dBm Hybrid Envelope Elimination and Restoration Power Amplifier for 802.11g WLAN Applications", IEEE Transactions on Microwave Theory and Techniques, Volume 54, Number 12, December 2006, pages 4086-4099.

[15] M. Vasic, O. Garcia, J.A. Oliver, P. Alou, J.A. Cobos, "Serial or Parallel Linear-assisted Switching Converter as Envelope Amplifier: Optimization and Comparison" IEEE Energy Conversion Congress and Exposition ECCE 2011.

[16] V. Yousefzadeh, E. Alarcon, D. Maksimovic, "Three-level buck converter for envelope tracking in RF power amplifier", IEEE Transactions on Power Electronics, Volume 21, Number 2, 2006
[17] M.Vasic, O.Garcia, J.A.Oliver, P.Alou, D.Diaz, J.A.Cobos. "Multilevel Power Supply for High Efficiency RF Amplifiers", IEEE Applied Power Electronics Conference APEC 2009

[18] D. Diaz, M. Vasic, P. Alou, O. Garcia, J.A. Oliver, J.A.; Cobos, "Comparison of two different cell topologies for a multilevel power supply to achieve high efficiency envelope amplifier', IEEE Energy Conversion Congress and Exposition ECCE 2009, pp. 25 - 30

[19] M. Rodriguez, P.F. Miaja, A. Rodriguez, J. Sebastian, "Multilevel converter for Envelope Tracking in RF power amplifiers", IEEE Energy Conversion Congress \& Exposition ECCE 2009.

[20] P. Miaja, M. Rodríguez, A. Rodríguez, J. Sebastián, "A linear assisted DC/DC converter for Envelope Tracking and Envelope Elimination and Restoration applications", IEEE Energy Conversion Congress \& Exposition ECCE 2010.

[21] A. Soto, J.A. Oliver, J.A. Cobos, J. Cezon, F. Arevalo, 'Power supply for a radio transmitter with modulated supply voltage", IEEE Applied Power Electronics Conference, APEC '04, Volume: 1, Feb. 2004 pp. 392 - 398.

[22] Z. Yang, Z. Xu, R. Zane, D. Maksimovic, "Wide-Bandwidth Digital Multi-Phase Controller", IEEE Power Electronics Specialists Conference PESC, 2006, pp. 1-7

[23] P. Cheng, M. Vasic, O. Garcia, J. A. Oliver, P. Alou, J. A. Cobos, "Multiphase buck converter with minimum time control strategy for RF envelope modulation", IEEE Applied Power Electronics Conference APEC 2011.

[24] D. Costinett, H. Nguyen, R. Zane, D. Maksimovic, "GaN-FET based dual active bridge de-de converter", IEEE Applied Power Electronics Conference, APEC 2011.

[25] M. Danilovic, Z. Chen, R. Wang, F. Luo, D. Boroyevich, P. Mattavelli "Evaluation of the switching characteristics of a Gallium nitride transistor" IEEE Energy Conversion Congress \& Exposition ECCE 2011.

[26] D. Cucak, M. Vasic, O. García, J. A. Oliver, P. Alou, J. A. Cobos, "Optimum Design of an Envelope Tracking Buck Converter for RF PA using GaN HEMTs", IEEE Energy Conversion Congress \& Exposition ECCE 2011. 